\title{
Should singleton birth weight standards be applied to identify small-for-gestational age twins?: analysis of a retrospective cohort study
}

Dongxin Lin ${ }^{1,2}$, Jiaming Rao ${ }^{1,2}$, Dazhi Fan ${ }^{1,2}$, Zheng Huang ${ }^{3}$, Zixing Zhou ${ }^{1,2}$, Gengdong Chen ${ }^{1,2}$, Pengsheng Li ${ }^{1,2}$, Xiafen Lu' ${ }^{2}$, Demei Lu $u^{1,2}$, Huishan Zhang ${ }^{1,2}$, Caihong Luo ${ }^{2}$, Xiaoling Guo ${ }^{1,2}$ and Zhengping Liu $^{1,2^{*}}$

\begin{abstract}
Background: Twin birth weight percentiles are less popular in clinical management among twin pregnancies compared with singleton ones in China. This study aimed to compare the incidence and neonatal outcomes of small for gestational age (SGA) twins between the use of singleton and twin birth weight percentiles.

Methods: This was a retrospective cohort study of 3,027 pregnancies with liveborn twin pairs at gestational age of $>28$ weeks. The newborns were categorized as SGA when a birthweight was less than the 10th percentile based on the singleton and twin references derived from Chinese population. Logistic regression models with generalized estimated equation (GEE) were utilized to evaluate the association between SGA twins and neonatal outcomes including neonatal unit admission, neonatal jaundice, neonatal respiratory distress (NRDS), neonatal asphyxia, ventilator support, hypoxic ischemic encephalopathy (HIE), bronchopulmonary dysplasia (BPD), necrotizing enterocolitis (NEC), intracranial hemorrhage (ICH), culture-proven sepsis, neonatal death within 28 days after birth as well as the composite outcome.

Results: The incidence of SGA was $33.1 \%$ based on the singleton reference and $7.3 \%$ based on the twin reference. Both of SGA newborns defined by the singleton and twin references were associated with increases in neonatal unit admission, neonatal jaundice and ventilator support. In addition, SGA newborns defined by the twin reference were associated with increased rates of BPD (aOR, $2.61 ; 95 \% \mathrm{Cl}: 1.18-5.78)$ as well as the severe composite outcome (aOR, 1.93; $95 \% \mathrm{Cl}: 1.07-3.47)$.

Conclusions: The use of singleton birth weight percentiles may result in misdiagnosed SGA newborns in twin gestations and the twin birth weight percentiles would be more useful to identify those who are at risk of adverse outcomes.
\end{abstract}

Keywords: Twins, Birth weight percentiles, Small for gestational age, Neonatal outcomes

\footnotetext{
* Correspondence: liuzphlk81@outlook.com

${ }^{1}$ Foshan Institute of Fetal Medicine, Southern Medical University Affiliated

Maternal \& Child Health Hospital of Foshan, 11 Renminxi Road, Guangdong 528000 Foshan, China

${ }^{2}$ Department of Obstetrics, Southern Medical University Affiliated Maternal \& Child Health Hospital of Foshan, 528000 Foshan, Guangdong, China

Full list of author information is available at the end of the article
}

(c) The Author(s). 2021 Open Access This article is licensed under a Creative Commons Attribution 4.0 International License, which permits use, sharing, adaptation, distribution and reproduction in any medium or format, as long as you give appropriate credit to the original author(s) and the source, provide a link to the Creative Commons licence, and indicate if changes were made. The images or other third party material in this article are included in the article's Creative Commons licence, unless indicated otherwise in a credit line to the material. If material is not included in the article's Creative Commons licence and your intended use is not permitted by statutory regulation or exceeds the permitted use, you will need to obtain permission directly from the copyright holder. To view a copy of this licence, visit http://creativecommons.org/licenses/by/4.0/. The Creative Commons Public Domain Dedication waiver (http://creativecommons.org/publicdomain/zero/1.0/) applies to the data made available in this article, unless otherwise stated in a credit line to the data. 


\section{Background}

Birth weight and fetal weight are common indicators of fetal growth. However, the terminology for newborns with abnormal growth is inconsistent. In the updated American College of Obstetricians and Gynecologist (ACOG) Practice Bulletin, fetal growth restriction (FGR) is defined based on a sonographic estimated fetal weight (EFW) less than 10th percentile for gestational age while small for gestational age (SGA) is defined based on a birth weight less than 10th percentile for gestational age [1]. FGR or SGA increases the risks of perinatal morbidity and mortality [2-4]. Furthermore, these categories of children are also at risks of long-term complications such as neurodevelopmental delay, adult obesity and metabolic diseases [5-8].

Over the last decades, the incidence of twin pregnancies has been rising mainly due to the significantly increased use of assisted reproductive technology (ART) and the delayed childbearing age [9-11]. Compared with singletons, twin pregnancies have higher risks of FGR or SGA. Therefore, correctly identifying those fetuses with abnormal growth is of great clinical significance for improving prediction of adverse outcomes and perinatal health care for twins. In fact, there remains controversy as to which reference should be used to classify SGA twins, mainly due to the geographic and ethnic disparities in fetal growth pattern. Twin-specific birth weight percentiles for gestational age have been established and updated from regional or national databases [12-20]. However, these tools seem not popular because of lack of linking data to perinatal outcomes. In contrast, the singleton references were commonly used in clinical practice and research work [21-23].

In this study, we compared the prevalence of SGA twins defined by the singleton-based and the twin-based birth weight percentiles and their associations with neonatal morbidity and mortality.

\section{Methods}

\section{Study design}

The retrospective cohort study included twin deliveries at a tertiary hospital in Foshan, China, from January 2012 to December 2020. This study was approved by the ethics committee of Southern Medical University Affiliated Maternal \& Child Health Hospital of Foshan (FSFY-2,019,042,006) and the ethics committee endorsed this research to waive the informed consent of the patients due to the retrospective design.

\section{Inclusion and exclusion criteria}

The inclusion criteria for current study were pregnancies with both living born fetuses at gestational age beyond 28 weeks. Pregnancies with congenital anomalies, twinto-twin transfusion (TTTS), monoamniotic twins, unknown chorionicity, intrauterine death and gestational age at delivery $<28$ weeks were excluded for analysis.

\section{Data collection}

All electric medical records of eligible pregnancies were systematically reviewed to obtain maternal and neonatal Information. Data on maternal age, parity, use of assisted reproductive technology, chorionicity, fetal gender, gestational complications (gestational diabetes mellitus, idiopathic jaundice of pregnancy and hypertensive disorder of pregnancy), maternal infections (syphilis and hepatitis B) and pre-existing hypertension and diabetes mellitus was collected. In the present study, the chorionicity was determined by sonographic examination and was confirmed by placental pathologic findings after birth, if available. The gestational age was calculated from the date of embryo transfer for IVF/ICSI pregnancies ( +14 days) and based on the last menstrual period for spontaneous pregnancies and was confirmed by sonography in the first trimester. HDPs included gestational hypertension and preeclampsia $(\mathrm{PE})$, which were diagnosed based on the criteria developed by ACOG [24]. A diagnosis of gestational diabetes mellitus (GDM) was made by oral $75 \mathrm{~g}$ glucose tolerance test (OGTT) between 24 and 28 weeks (fasting plasma glucose $\geq 5.1$ $\mathrm{mmol} / \mathrm{l}$ or 1 -hour plasma glucose $\geq 10.0 \mathrm{mmol} / \mathrm{l}$ or 2 hour plasma glucose $\geq 8.5 \mathrm{mmol} / \mathrm{l})$. SGA was defined when a birthweight was less than the 10th percentile. We utilized population-based birthweight percentiles in Chinese singletons and twins $[15,25]$. These references were chosen because of their large size of study population and adjustment for fetal sex.

\section{Outcomes of interest}

The primary outcome was neonatal unit admission. The secondary outcomes included neonatal jaundice, neonatal respiratory distress (NRDS), neonatal asphyxia, ventilator support, hypoxic ischemic encephalopathy (HIE), bronchopulmonary dysplasia (BPD), necrotizing enterocolitis (NEC), intracranial hemorrhage (ICH), culture-proven sepsis and neonatal death within 28 days after birth. We also defined a composite outcome as any occurrence of HIE, NEC, ICH, BPD, sepsis as well as neonatal death.

\section{Statistical analysis}

The baseline characteristics of the included pregnancies were reported as mean \pm standard deviation (SD) or frequency with its percentage, where appropriate. When analyzing the neonatal outcomes, the unit of analysis was the newborn. In this regard, logistic regression analyses were performed using a generalized estimating equation (GEE) approach to address the intertwin correlation. The adjusted odds ratios (ORs) and $95 \%$ 
confidence intervals (CIs) were calculated by performing multivariable models controlled for gestational age at delivery, nulliparity, maternal age, chorionicity, use of ART, GDM and pre-eclampsia. We also performed sensitivity analysis after excluding women with complications during pregnancy (ICP, HDPs, GDM), pre-existing hypertension or diabetes mellitus and maternal infection (syphilis and hepatitis B). All two tailed $P$-values $<0.05$ were considered statistical significance. The statistical analyses were performed using Stata, version 15.1.

\section{Results}

The baseline characteristics of the included pregnancies were shown in Table 1. During the study period, 3,027 twin pregnancies with 6,054 newborns were eligible for the study. The maternal age was $30.8 \pm 4.6$ (range: $17-$ 52 ). Over half of the included pregnancies were nulliparity (67.2\%) and ART conceived (65.4\%). Monochorionic twins accounted for $17.9 \%$. The proportion of fetal gender combination was $34.8 \%, 28.9$ and $36.3 \%$ for male-

Table 1 Baseline characteristics of included pregnancies $(N=3027)$

\begin{tabular}{ll}
\hline Variables & $30.8 \pm 4.6$ (range: 17-52) \\
\hline Maternal age & $2034(67.2)$ \\
Nulliparity & $1981(65.4)$ \\
ART conceived pregnancies & $542(17.9)$ \\
Monochorionic twins & \\
Fetal sex & $1053(34.8)$ \\
Male-male & $874(28.9)$ \\
Female-female & $1100(36.3)$ \\
Male-female & $29(1.0)$ \\
Preexisting diabetes mellitus & $24(0.8)$ \\
Preexisting hypertension & $8(0.3)$ \\
Syphilis & $234(7.7)$ \\
Hepatitis B & $342(11.3)$ \\
Hypertensive disorders of pregnancy & $615(20.3)$ \\
Gestational diabetes mellitus & $81(2.7)$ \\
Idiopathic jaundice of pregnancy & $2974(98.3)$ \\
Caesarean section & $35.8 \pm 1.8$ \\
Gestational age at delivery &
\end{tabular}

ART assisted reproductive technology male, female-female and male-female, respectively. The incidence of hypertensive disorders of pregnancy was $11.3 \%$ and that of GDM was $20.3 \%$. The incidences of idiopathic jaundice of pregnancy, pre-existing diabetes mellitus, pre-existing hypertension and syphilis were low (2.7\%, $1.0 \%, 0.8$ and $0.3 \%$, respectively). The incidence of Hepatitis B was $7.7 \%$. The vast majority of included pregnancies $(98.3 \%)$ underwent caesarean section. The gestational age at delivery was $35.8 \pm 1.8$ weeks. The incidence of SGA fetuses was $33.1 \%$ based on the singleton standards and $7.3 \%$ based on twin standards. The incidence of LGA fetuses was 0.3 and $4.8 \%$ based on singleton and twin standards, respectively.

In the multivariable analyses, as shown in Table 2, we found that the SGA newborns defined based on singleton standards were associated with increased odds ratios of neonatal unit admission (aOR, 2.11; $95 \%$ CI: $1.84-$ 2.41), neonatal jaundice (aOR, 1.99; $95 \%$ CI: 1.73-2.29) and ventilator support (aOR, 1.45; $95 \%$ CI: 1.09-1.91) but were not associated with any other morbidities and mortality.

Based on the twin standards, similarly, SGA newborns were associated with neonatal unit admission $(\mathrm{aOR}, 7.72$; $95 \%$ CI: 6.01-9.91), neonatal jaundice (aOR, 4.09; $95 \%$ CI: 3.30-5.09) and ventilator support (aOR, 1.94; $95 \%$ CI: 1.32-2.85). In addition, they were associated with increased odds ratios of BPD (aOR, 2.61; $95 \%$ CI: 1.18 5.78) as well as the severe composite outcome (aOR, 1.93; 95 \% CI: 1.07-3.47) (Table 3).

After excluding women with complications during pregnancy (ICP, HDPs and GDM), pre-existing hypertension or diabetes mellitus or maternal infections, SGA newborns, irrespective of birth weight percentiles, were associated with increased incidences of neonatal unit admission, neonatal jaundice and ventilator support. However, the SGA newborns did not have significantly increased incidences of severe morbidities and mortality. The results were supplemented in Table S1 and Table S2.

\section{Discussion}

Our analysis of retrospective data found that the use of singleton birth weight percentiles resulted in a higher prevalence of SGA twins compared with the use of twin birth weight percentiles. Both of SGA twins defined by singleton and twin birth weight standards were associated with common morbidities such as neonatal unit admission, neonatal jaundice and ventilator support. In addition, SGA twins defined by twin standards were associated with BPD and the severe composite outcome whereas those defined by singleton standards were not. 
Table 2 Analysis of association between SGA twin newborns and neonatal outcomes based on singleton birthweight reference

\begin{tabular}{lllllll}
\hline Outcomes & $\begin{array}{l}\text { Non-SGA } \\
(\boldsymbol{n}=\mathbf{4 , 0 5 2})\end{array}$ & $\begin{array}{l}\text { SGA } \\
(\boldsymbol{n}=\mathbf{2 , 0 0 2})\end{array}$ & Unadjusted OR (95\% Cl) & $\boldsymbol{P}$-value & Adjusted OR (95 \% CI) $^{\mathbf{a}}$ & $\boldsymbol{P}$-value \\
\hline Neonatal unit admission & $1629(40.2)$ & $878(43.9)$ & $1.31(1.20-1.44)$ & $<0.001$ & $2.11(1.84-2.41)$ & $<0.001$ \\
Neonatal jaundice & $1191(29.4)$ & $627(31.3)$ & $1.27(1.15-1.40)$ & $<0.001$ & $1.99(1.73-2.29)$ & $<0.001$ \\
NRDS & $413(10.2)$ & $120(6.0)$ & $0.82(0.72-0.94)$ & 0.004 & $1.11(0.88-1.41)$ & 0.376 \\
Neonatal asphyxia & $108(2.7)$ & $34(1.7)$ & $0.70(0.49-0.99)$ & 0.045 & $0.96(0.63-1.44)$ & 0.828 \\
Ventilator support & $351(8.7)$ & $110(5.5)$ & $0.78(0.65-0.94)$ & 0.008 & $1.45(1.09-1.91)$ & 0.010 \\
HIE & $12(0.3)$ & $6(0.3)$ & $1.01(0.38-2.70)$ & 0.980 & $1.04(0.38-2.86)$ & 0.934 \\
ICH & $17(0.4)$ & $8(0.4)$ & $0.97(0.42-2.26)$ & 0.941 & $1.09(0.46-2.61)$ & 0.846 \\
Sepsis & $50(1.2)$ & $18(0.9)$ & $0.76(0.44-1.30)$ & 0.312 & $1.20(0.67-2.14)$ & 0.533 \\
BPD & $50(1.2)$ & $14(0.7)$ & $0.66(0.37-1.17)$ & 0.157 & $1.61(0.80-3.21)$ & 0.180 \\
Neonatal death & $16(0.4)$ & $8(0.4)$ & $1.01(0.43-2.37)$ & 0.982 & $1.39(0.56-3.45)$ & 0.475 \\
Severe composite outcome & $101(2.5)$ & $28(1.4)$ & $0.67(0.45-1.00)$ & 0.051 & $1.34(0.83-2.16)$ & 0.230 \\
\hline
\end{tabular}

${ }^{a}$ Adjusted for gestational age at delivery, nulliparity, maternal age, chorionicity, use of ART, PE and GDM. NRDS, neonatal respiratory distress syndrome; HIE hypoxic ischemic encephalopathy, ICH intracranial hemorrhage, BPD bronchopulmonary dysplasia, OR odds ratio, $A R T$ assisted reproductive technology, $P E$ preeclampsia, GDM, gestational diabetes mellitus

The decision-making of clinical management on twin gestations depends on the chorionicity and the fetal growth [26-29]. Some clinicians identify abnormal growth among twins by using weight discordance, which has been proved to be associated with neonatal morbidity and be detected prenatally by ultrasound [30-32], although using discordant weight as the indication for delivery is still controversial. Using birth or estimated weight percentile is an effective way to identify growth-restricted fetuses. The prevalence of SGA twins depends on the definition used. Due to the lack of reference, growth standards for singletons are commonly used to assess twin growth in clinical practice [23, 33]. Previous studies showed that the growth trajectory of twins diverges from the one of singletons in the third trimester [13, 19, 34, 35]. Based on current study population, the use of singleton birth weight standards obtained a prevalence of $33.1 \%$ in SGA newborns, which was nearly 3.5 -fold higher than that by using twin standards. Similarly, the previous data from Houston, Texas [36], reported that the use of singleton growth standards misclassified twins as SGA, resulting in a 7 -fold higher incidence of SGA fetuses compared with the use of twin growth standards. Also, another study of Nowacka et al. [37] showed the implementation of twin-specific nomograms decreased the rate of SGA twins, in

Table 3 Analysis of association between SGA twin newborns and neonatal outcomes based on twin birthweight reference

\begin{tabular}{|c|c|c|c|c|c|c|}
\hline Outcomes & $\begin{array}{l}\text { Non-SGA } \\
(n=5,611)\end{array}$ & $\begin{array}{l}\text { SGA } \\
(n=443)\end{array}$ & Unadjusted OR (95\% Cl) & $P$-value & Adjusted OR $(95 \% \mathrm{Cl})^{*}$ & $P$-value \\
\hline Neonatal unit admission & $2153(38.4)$ & $354(79.9)$ & $3.68(3.13-4.34)$ & $<0.001$ & $7.72(6.01-9.91)$ & $<0.001$ \\
\hline Neonatal jaundice & $1554(27.7)$ & $264(59.6)$ & $2.58(2.20-3.03)$ & $<0.001$ & $4.09(3.30-5.09)$ & $<0.001$ \\
\hline NRDS & $475(8.5)$ & $58(13.1)$ & $1.05(0.85-1.30)$ & 0.674 & $1.25(0.90-1.75)$ & 0.187 \\
\hline Neonatal asphyxia & $128(2.3)$ & $14(3.2)$ & $1.24(0.75-2.07)$ & 0.397 & $1.22(0.69-2.13)$ & 0.498 \\
\hline Ventilator support & $410(7.3)$ & $51(11.5)$ & $1.35(1.05-1.75)$ & 0.021 & $1.94(1.32-2.85)$ & 0.001 \\
\hline HIE & $15(0.3)$ & $3(0.7)$ & $2.54(0.73-8.82)$ & 0.141 & $2.06(0.57-7.36)$ & 0.268 \\
\hline $\mathrm{ICH}$ & $21(0.4)$ & $4(0.9)$ & $2.50(0.86-7.22)$ & 0.091 & $2.05(0.68-6.13)$ & 0.201 \\
\hline Sepsis & $60(1.1)$ & $8(1.8)$ & $1.60(0.75-3.41)$ & 0.219 & $1.54(0.71-3.31)$ & 0.273 \\
\hline BPD & $54(1.0)$ & $10(2.3)$ & $2.33(1.20-4.52)$ & 0.013 & $2.61(1.18-5.78)$ & 0.018 \\
\hline Neonatal death & $19(0.3)$ & $5(1.1)$ & $3.00(1.08-8.28)$ & 0.034 & $2.34(0.82-6.71)$ & 0.113 \\
\hline Severe composite outcome & $113(2.0)$ & $16(3.6)$ & $1.74(1.04-2.91)$ & 0.035 & $1.93(1.07-3.47)$ & 0.028 \\
\hline
\end{tabular}

${ }^{a}$ Adjusted for gestational age at delivery, nulliparity, maternal age, chorionicity, use of ART, PE and GDM. NRDS neonatal respiratory distress syndrome, HIE, hypoxic ischemic encephalopathy, $I C H$ intracranial hemorrhage, BPD bronchopulmonary dysplasia, $O R$ odds ratio; $A R T$ assisted reproductive technology, $P E$ preeclampsia, GDM gestational diabetes mellitus 
comparison to using singleton-specific nomograms. The misdiagnosis of SGA could result in subsequent mistakes in clinical decision-making on the timing of delivery of SGA twin pregnancies.

Despite several birth weight standards for twin gestations has been published in recent years in China $[15,33,38]$, these standards seem not promoted. We undertook a local validation to assess the appropriateness of the chosen standards. The analysis of neonatal outcomes showed that SGA twin, defined by either singleton or twin standards, were associated with significant increases in neonatal unit admission, neonatal jaundice and ventilator support. Based on the multiple analyses, these risks of morbidities are noted to be higher when using the twin standards than the singleton standards. The results were similar to those of sensitivity analysis performed among health women. Moreover, the twin standards showed an advantage for identifying newborns who were at risks of BPD, neonatal death as well as the composite severe outcome. These findings were consistent with that of previous studies [36, 37, 39]. Mendez-Figueroa et al. [36] found increased rates of composite morbidity, Apgar score $<4$ at $5 \mathrm{~min}$, mechanical ventilation, seizures, stillbirth as well as neonatal death in SGA fetuses defined by twin monogram whereas only increased rates of composite morbidity and stillbirth in SGA fetuses defined by singleton monogram [36]. Nowaka et al. [37] also found that estimating twin growth with customized charts provides better prognosis of adverse neonatal outcomes in the SGA twins compared with singleton nomograms. Giorgione et al. [39] found that twin charts identified a higher percentage of adverse outcomes (perinatal death, neonatal unit admission, preterm birth $<34$ weeks and HDP) among SGA newborns than singleton charts. The twin birth weight percentiles were more applicable for identifying neonatal morbidities and mortality among twins. In this regard, the use of twin birth weight percentiles should be proposed and promoted in the clinical practice.

While the strengths in current study were large size of study population, several limitations should be acknowledged in the interpretation of the current results. First, some potential for bias could not be avoided due to the retrospective nature. Data regarding some potential confounders or neonatal outcomes (for example, maternal BMI, Apgar score) was unavailable or incomplete. Second, the chosen birth weight standards derived from Chinese population and therefore the conclusion might not be applicable to populations in other countries [15]. Third, sonographic EFW was not available in our retrospective database, therefore generalization of the current results to EFW deserves to be further studied.

\section{Conclusions}

The use of singleton birth weight percentiles among twins contributes to higher prevalence of SGA newborns. The twin standards are more applicable for the prediction of adverse neonatal outcomes among twins. The use of the twin birth weight references in twin gestations should be proposed and promoted in clinical practice.

\begin{abstract}
Abbreviations
ACOG: American College of Obstetricians and Gynecologist; ART: assisted reproductive technology; DCDA: dichorionic-diamnionic; EFW: estimated fetal weight; FGR: fetal growth restriction; MCDA: monochorionic-diamnionic; GEEs: general estimated equations; OGTT: glucose tolerance test;

GDM: gestational diabetes mellitus; HDP: hypertensive disorder of pregnancy; ICP: idiopathic jaundice of pregnancy; PE: pre-eclampsia; SGA: small for gestational age; TTS: twin-to-twin transfusion; BPD: bronchopulmonary dysplasia; HIE: hypoxic ischemic encephalopathy; NEC: necrotizing enterocolitis; ICH: intracranial hemorrhage; NRDS: neonatal respiratory distress syndrome
\end{abstract}

\section{Supplementary information}

The online version contains supplementary material available at https://doi. org/10.1186/s12884-021-03907-1.

\section{Additional file 1.}

\section{Acknowledgements}

We thank all the participants who were included for this study.

\section{Authors' contributions}

D.L and C.L contributed to study conception and design. X.L, Z.Z and H.Z collected the data. J.R and P.L examined the data integrity and accuracy. D.L and D.F performed data analysis. G.C and J.R provided statistical advices. C.L, D.L (Demei Lu) and X.G contributed to result interpretation. D.L drafted the manuscript. G.C and Z.H revised the manuscript. Z.L provided helpful suggestions for manuscript revision. All the author read and approved the final manuscript

\section{Funding}

Not applicable.

\section{Availability of data and materials}

The datasets used or analyzed in current study are available from the corresponding author on reasonable requests.

\section{Declarations}

Ethics approval and consent to participate

This study was approved by the ethics committee of Southern Medical University Affiliated Maternal \& Child Health Hospital of Foshan (ethics approval number: FSFY-2019042006). Due to the respective nature of current study, the consent from each subject were waived by the ethics committee of Southern Medical University Affiliated Maternal \& Child Health Hospital of Foshan. All personal identifiers were anonymized prior to analysis. All methods were performed in accordance with the relevant guidelines and regulations.

\section{Consent for publication}

Not applicable.

Competing interest

The authors declare no competing interest. 


\section{Author details}

${ }^{1}$ Foshan Institute of Fetal Medicine, Southern Medical University Affiliated Maternal \& Child Health Hospital of Foshan, 11 Renminxi Road, Guangdong 528000 Foshan, China. ${ }^{2}$ Department of Obstetrics, Southern Medical University Affiliated Maternal \& Child Health Hospital of Foshan, 528000 Foshan, Guangdong, China. ${ }^{3}$ The First Affiliated Hospital of Guangdong Pharmaceutical University, 510030 Guangzhou, Guangdong, China.

Received: 8 April 2021 Accepted: 24 May 2021

Published online: 25 June 2021

\section{References}

1. ACOG Practice Bulletin No. 204. Fetal Growth Restriction. Obstet Gynecol. 2019;133(2):e97-e109.

2. Selvaratnam RJ, Wallace EM, Treleaven S, Hooper SB, Davis PG, Davey MA. Does detection of fetal growth restriction improve neonatal outcomes? J Paediatr Child Health. 2020;57(5):677-83.

3. Longo S, Bollani L, Decembrino L, Di Comite A, Angelini M, Stronati M. Short-term and long-term sequelae in intrauterine growth retardation (IUGR). J Matern Fetal Neonatal Med. 2013;26(3):222-5.

4. Pels A, Beune IM, van Wassenaer-Leemhuis AG, Limpens J, Ganzevoort W. Early-onset fetal growth restriction: a systematic review on mortality and morbidity. Acta Obstet Gynecol Scand. 2020;99(2):153-66.

5. Lucaccioni L, Boncompagni A, Pugliese M, Talucci G, Della Casa E, Bertoncelli N, Coscia A, Bedetti L, Berardi A, lughetti L et al. Subtle impairment of neurodevelopment in infants with late fetal growth restriction. J Matern Fetal Neonatal Med. 2021:1-8. Epub ahead of print. PMID: 33455501

6. Sacchi C, Marino C, Nosarti C, Vieno A, Visentin S, Simonelli A. Association of intrauterine growth restriction and small for gestational age status with childhood cognitive outcomes: a systematic review and meta-analysis. JAMA Pediatr. 2020;174(8):772-81.

7. Katanoda K, Noda M, Goto A, Mizunuma H, Lee JS, Hayashi K. Impact of birth weight on adult-onset diabetes mellitus in relation to current body mass index: The Japan Nurses' Health Study. J Epidemiol. 2017;27(9):428-34.

8. Savchev S, Sanz-Cortes M, Cruz-Martinez R, Arranz A, Botet F, Gratacos E, Figueras F. Neurodevelopmental outcome of full-term small-for-gestationalage infants with normal placental function. Ultrasound Obstet Gyneco. 2013;42(2):201-6.

9. Smits J, Monden C. Twinning across the developing world. PloS one. 2011; 6(9):e25239.

10. Adashi EY, Gutman R. Delayed childbearing as a growing, previously unrecognized contributor to the national plural birth excess. Obstet Gynecol. 2018;132(4):999-1006.

11. Deng C, Dai L, Yi L, Li X, Deng K, Mu Y, Wang K, Tao J, Li Q, Xu L. Temporal trends in the birth rates and perinatal mortality of twins: a population-based study in China. PloS one 2019;14(1):e0209962.

12. Min SJ, Luke B, Gillespie B, Min L, Newman RB, Mauldin JG, Witter FR, Salman FA, O'Sullivan MJ. Birth weight references for twins. Am J Obstet Gynecol. 2000;182(5):1250-7.

13. Sankilampi U, Hannila ML, Saari A, Gissler M, Dunkel L. New populationbased references for birth weight, length, and head circumference in singletons and twins from 23 to 43 gestation weeks. Ann Med. 2013;45(56):446-54.

14. Li Z, Umstad MP, Hilder L, Xu F, Sullivan EA. Australian national birthweight percentiles by sex and gestational age for twins, 2001-2010. BMC Pediatr. 2015;15:148.

15. Dai L, Deng C, Li Y, Yi L, Li X, Mu Y, Li Q, Yao Q, Wang Y. Population-based birth weight reference percentiles for Chinese twins. Ann Med. 2017;49(6): 470-8.

16. Arbuckle TE, Wilkins R, Sherman GJ. Birth weight percentiles by gestational age in Canada. Obstet Gynecol. 1993;81(1):39-48.

17. Ooki S, Yokoyama Y. Reference birth weight, length, chest circumference, and head circumference by gestational age in Japanese twins. J Epidemiol. 2003;13(6):333-41.

18. Lee JK, Jang HL, Kang BH, Lee KS, Choi YS, Shim KS, Lim JW, Bae CW, Chung $\mathrm{SH}$. Percentile distributions of birth weight according to gestational ages in Korea (2010-2012). J Korean Med Sci. 2016;31(6):939-49.

19. Horst N, Dera-Szymanowska A, Breborowicz GH, Szymanowski K. Outcome dependent twin growth curves based on birth weight percentiles for Polish population. J Matern Fetal Neonatal Med. 2020:1-6. Epub ahead of print. PMID: 32633159

20. Bricelj K, Blickstein I, Bržan-Šimenc G, Janša V, Lučovnik M, Verdenik I, Trojner-Bregar A, Tul N. Growth curves for twins in Slovenia. J Matern Fetal Neonatal Med. 2017;30(4):479-81.

21. Fox NS, Saltzman DH, Oppal S, Klauser CK, Gupta S, Rebarber A. The relationship between preeclampsia and intrauterine growth restriction in twin pregnancies. Am J Obstet Gynecol. 2014;211(4):422.e421-425.

22. Sparks TN, Nakagawa S, Gonzalez JM. Hypertension in dichorionic twin gestations: how is birthweight affected? J Matern Fetal Neonatal Med. 2017; 30(4):380-5.

23. Zhang J, Mikolajczyk R, Lei X, Sun L, Yu H, Cheng W. An adjustable fetal weight standard for twins: a statistical modeling study. BMC Med. 2015;13:159.

24. American College of Obstetricians and Gynecologists. Hypertension in pregnancy. Report of the American College of Obstetricians and Gynecologists' Task Force on Hypertension in Pregnancy. Obstet Gynecol. 2013;122(5):1122-31

25. Dai L, Deng C, Li Y, Zhu J, Mu Y, Deng Y, Mao M, Wang Y, Li Q, Ma S et al. Birth weight reference percentiles for Chinese. PloS one. 2014;9(8):e104779.

26. Danon D, Sekar R, Hack KEA, Fisk NM. Increased stillbirth in uncomplicated monochorionic twin pregnancies: a systematic review and meta-analysis. Obstet Gynecol. 2013;121(6):1318-26.

27. Burgess $J$, Unal ER, Nietert PJ, Newman RB. Risk of late-preterm stillbirth and neonatal morbidity for monochorionic and dichorionic twins. Am J Obstet Gynecol. 2014;210(6):578.e571-579.

28. Lee YM, Wylie BJ, Simpson LL, D'Alton ME. Twin chorionicity and the risk of stillbirth. Obstet Gynecol. 2008;111(2 Pt 1):301-8.

29. Behrendt N, Galan HL. Fetal growth in multiple gestations: evaluation and management. Obstet Gynecol Clin North Am. 2021;48(2):401-17.

30. Di Mascio D, Acharya G, Khalil A, Odibo A, Prefumo F, Liberati M, Buca D, Manzoli L, Flacco ME, Brunelli R et al. Birthweight discordance and neonatal morbidity in twin pregnancies: a systematic review and meta-analysis. 2019; 98(10):1245-57.

31. Leombroni M, Liberati M, Fanfani F, Pagani G, Familiari A, Buca D, Manzoli L, Scambia G, Rizzo G, D’Antonio F. Diagnostic accuracy of ultrasound in predicting birth-weight discordance in twin pregnancy: systematic review and meta-analysis. 2017:50(4):442-50.

32. D'Antonio F, Khalil A, Dias T, Thilaganathan B. Weight discordance and perinatal mortality in twins: analysis of the Southwest Thames Obstetric Research Collaborative (STORK) multiple pregnancy cohort. Ultrasound Obstet Gynecol. 2013;41(6):643-8.

33. Miao H, Yao F, Wu Y, Zhang X, He R, Li B, Zhao Q. Birth weight percentiles by sex and gestational age for twins born in southern China. Sci Rep. 2019; 9(1):757.

34. Liu YC, Blair EM. Predicted birthweight for singletons and twins. Twin Res. 2002;5(6):529-37.

35. Grantz KL, Grewal J, Albert PS, Wapner R, D'Alton ME, Sciscione A, Grobman WA, Wing DA, Owen J, Newman RB et al. Dichorionic twin trajectories: the NICHD Fetal Growth Studies. Am J Obstet Gynecol. 2016;215(2):221.e221221.e216.

36. Mendez-Figueroa H, Truong VIT, Pedroza C, Chauhan SP. Growth among twins: use of singleton versus twin-specific growth nomograms. Am J Perinatol. 2018;35(2):184-91.

37. Nowacka U, Kosińska-Kaczyńska K, Krajewski P, Saletra-Bielińska A, Walasik I, Szymusik I. Predictive accuracy of singleton versus customized twin growth chart for adverse perinatal outcome: a cohort study. Int J Environ Res Public Health. 2021;18(4):2016.

38. Zhang B, Cao Z, Zhang Y, Yao C, Xiong C, Zhang Y, Wang Y, Zhou A. Birthweight percentiles for twin birth neonates by gestational age in China. Sci Rep. 2016:6:31290.

39. Giorgione V, Briffa C, Di Fabrizio C, Bhate R, Khalil A. Perinatal outcomes of small for gestational age in twin pregnancies: twin vs. singleton charts. J Clin Med. 2021;10(4)

\section{Publisher's Note}

Springer Nature remains neutral with regard to jurisdictional claims in published maps and institutional affiliations. 